\title{
DE TRABAJADORES A SOLDADOS: TRABAJO FORZADO Y CONSCRIPCIÓN EN LA GUINEA ESPAÑOLA Y LA NIGERIA ORIENTAL, 1930-1970'
}

\section{WORKERS TO SOLDIERS: COERCED LABOR AND CONSCRIPTION IN SPANISH GUINEA AND EASTERN NIGERIA, 1930-1970}

Samuel Fury Daly

Duke University

\section{RESUMEN}

Este artículo conecta dos formas de coacción que raras veces son analizadas de forma conjunta en los estudios sociales y de la guerra. Se trata de la experiencia de la mano de obra forzosa emigrante y la experiencia de ser soldado. Los nigerianos orientales, y especialmente los del grupo étnico igbo, fueron sometidos a estas dos formas de coerción en los años 60, que para los muchos hombres que las experimentaron quedaron relacionadas entre sí. El reclutamiento para labores agrícolas en la isla de Fernando Po, en la Guinea española, desde los años 30 a los 60 y el reclutamiento en el ejército de la República secesionista de Biafra durante la Guerra Civil nigeriana (1967-1970) fueron fenómenos contemporáneos entre sí, siguiendo en ambos casos patrones muy similares de violencia y arbitrariedad. Analizar ambos episodios de la historia de la Nigeria oriental en un solo marco interpretativo sugiere que, para aquéllos implicados, la línea entre el servicio militar y el trabajo forzoso fue tenue.

Palabras clave: Biafra, Nigeria, Guinea Ecuatorial, trabajo, modo de hacer la guerra

\section{ABASTRACT}

This article connects two forms of compulsion which are seldom considered together in studies of war and society. These are the experience of coerced migrant labor, and the experience of being a soldier. Eastern Nigerians, and especially members of the lgbo ethnic group, were subjected to these two distinct forms of coerced in the 1960s, which to many of the men who experienced them were related to one another. Recruitment for agricultural labor on the island of Fernando Po in Spanish Guinea between the 1930s and 1960s and recruitment into the army of the secessionist Republic of Biafra during the $\mathrm{Ni}$ gerian Civil War (1967-1970) were contemporaneous with one another, and they followed similar patterns of violence and arbitrariness. Considering these two episodes in eastern Nigeria's history in one frame suggests that, to those involved, the line between military service and coerced labor was indistinct.

Keywords: Biafra, Nigeria, Equatorial Guinea, labor, warfare.

1 Traducción realizada por David Alegre Lorenz. 


\section{RESUM \\ De treballadors a soldats: treball forçat i reclutament a la Guinea Espanyola i la Nigèria oriental, 1930-1970}

Aquest article connecta dues formes de coacció que poques vegades són analitzades de forma conjunta en els estudis socials i de la guerra. Es tracta de la experiència de la mà d'obra forçosa emigrant i l'experiència de ser soldat. Els nigerians orientals, $i$ especialment els del grup ètnic igbo, van ser sotmesos a les dues formes de coerció durant els anys 60, que van quedar relacionades entre sí en el cas de molts homes que van experimentar-les. El reclutament per a treballs agrícoles a la illa de Fernando Po, part de la Guinea espanyola, des dels anys 30 als $60 \mathrm{i}$ el reclutament dins de l'exèrcit de la República secessionista de Biafra durant la Guerra Civil nigeriana (1967-1970) van ser fets contemporanis entre sí, seguint en els dos casos patrons molt semblants de violència i arbitrarietat. Analitzar ambdós episodis de la història de Nigèria oriental en un sol marc interpretatiu suggereix que, per aquells implicats, la línia entre el servei militar i el treball forçat va ser molt borrosa.

Paraules clau: Biafra, Nigèria, Guinea Equatorial, treball, mode de fer la guerra. 
En una entrevista realizada en 2014, un veterano del ejército secesionista de la República de Biafra recordaba su experiencia como soldado raso durante la guerra civil nigeriana. A sus ojos aparecía como un periodo de grandes privaciones y dificultades, tanto que su patriotismo hacia el nuevo país quedó rápidamente ensombrecido por las condiciones de su servicio militar. Reclutado en un mercado a finales de 1968, fue sometido a un breve y brutal periodo de adiestramiento en un campamento militar del ejército cerca de Orlu, destinado a una unidad de jóvenes conscriptos y enviado al frente. Una vez allí estuvo ocupado la mayor parte del tiempo en cavar trincheras. Tal y como le ocurrió a muchos otros conscriptos, no recibió ni un uniforme ni un arma, al tiempo que se le ordenó compartir un rifle con otros tres hombres. La comida era escasa, sus movimientos eran estrictamente controlados y era humillado de forma habitual por sus superiores. "Sin embargo", recordaba, "nada de aquello me resultaba extraño, ya que había estado en Fernando Po" . ${ }^{2}$ Así pues, la conexión que establecía este antiguo soldado entre su servicio militar y su anterior experiencia como trabajador emigrante en las plantaciones de cacao de la Guinea española, frente a la costa de Nigeria oriental, sugiere una continuidad entre el trabajo forzoso y la vida del soldado que probablemente compartió con muchos otros reclutas.

La historia de la emigración laboral de los igbo a Fernando Po ha permanecido en el olvido durante mucho tiempo, sin embargo esta historia jugó un pequeño aunque notable papel en la historia de la guerra civil de $\mathrm{Ni}$ geria. Para muchos de los que apoyaron la declaración de independencia de Biafra, la percepción de haber sido "abandonados" por los gobiernos británico y nigeriano en Fernando Po contribuyó a aportar un argumento convincente para la secesión de la República de Biafra frente a Nigeria. Por lo general, los argumentos sobre el fracaso del gobierno nigeriano a la hora de proteger la vida y los intereses de los igbos fueron movilizados en relación a los actos de violencia étnica que tuvieron lugar al norte de Nigeria en 1966 contra dicha comunidad. Sin embargo, la experiencia de los igbos en la Guinea española también estaba presente en la mente de

2 Entrevista con Johnson Okeke, Okpara Avenue, Enugu, 10 de agosto de 2014. 
muchos de los habitantes de Biafra. Este artículo no defiende que existiera una línea directa que condujera de los sucesos de Fernando Po al estallido de la guerra civil en Nigeria. No obstante, es importante tener en cuenta las diferentes vías a través de las cuales la larga y agónica crisis de la emigración de los igbos a Fernando Po dio lugar a los marcos de referencia de los igbos y a su particular modo de entender su lugar en Nigeria. Además, para algunos soldados biafreños su estancia en el ejército de Biafra y su experiencia como trabajadores forzosos en la Guinea española estaban interconectadas. Esto pone de relieve de qué modo la conscripción y el trabajo forzoso pueden llegar a confundirse entre sí, al menos para aquellos que experimentaron ambos. Así pues, por medio de documentación procedente de los archivos del consulado británico en Fernando Po este artículo describe la experiencia de los igbos que fueron trasladados a la Guinea española como trabajadores entre los años 30 y 60 . A continuación, cambiando el foco a la propia Nigeria oriental analiza los mecanismos de reclutamiento en el ejército de la secesionista República de Biafra en el marco de la guerra civil nigeriana (1967-1970), identificando el solapamiento entre estos dos regímenes de "trabajo" forzoso -uno económico y el otro militar.

Habitualmente, la guerra civil de Nigeria es recordada como un conflicto en que los mercenarios jugaron un papel importante, especialmente en el bando biafrano. De hecho, en los primeros dieciocho meses de conflicto el gobierno de Biafra experimentó con el uso de mercenarios, incluyendo europeos, americanos, sudafricanos y rodesios. Sin embargo, rápidamente los líderes militares biafranos se volvieron críticos frente a la presencia de mercenarios; una serie de fracasos tácticos y actos de insubordinación, junto con el alto coste de utilizar "soldados de fortuna" de origen foráneo dejaron claro que la guerra no podría ganarse por un ejército liderado por un puñado de extranjeros -al menos algunos de ellos eran insensatos e impulsivos. Una versión ampliamente divulgada cuenta que el jefe de estado de Biafra decidió expulsar a los mercenarios en 1968 después de ser reprendido por uno de ellos, quien a su vez se encontraba claramente bajo los efectos del alcohol. El papel de esos mercenarios extranjeros, extravagante al igual que lo fue su comportamiento en líneas generales, fue exagerado en las crónicas periodísticas de la guerra, algo que ha continuado vivo dentro de muchos relatos históricos de Biafra. Sin embargo, en lo que se refiere a la comprensión del conflicto, fue mucho más importante la experiencia de los soldados ordinarios de origen biafrano, muchos de los cuales eran conscriptos que por lo general no atraían la atención de la prensa internacional. Son estos mercenarios, más que los mercenarios que ocuparon los titulares en la época, quienes se sitúan en el centro el presente análisis. 
Ligar la historia de la emigración laboral a Fernando Po y la guerra civil de Nigeria modifica la amplia historia de la emigración africana por motivos de trabajo. En el pasado, los historiadores de África vieron ésta habitualmente como un fenómeno interno de las colonias, y desde regiones pobres - improductivas a otros espacios donde se producían cultivos industriales o donde eran extraídos minerales. ${ }^{3}$ La emigración interterritorial en el África colonial es una preocupación historiográfica relativamente reciente; aunque fue un objeto preferente de atención por parte de teóricos y administradores coloniales, durante el periodo en que el análisis histórico del colonialismo se expandió, la historiografía de las emigraciones coloniales por lo general no lo hizo. Como han demostrado trabajos recientes, la emigración laboral africana cruzó de forma recurrente las fronteras de territorios individuales y, también, de imperios europeos. El análisis de Isaie Dougnon sobre la emigración laboral desde el País Dogón a la Costa de Oro discurre por premisas similares a las de este artículo: una de reclutamiento depredador de mano de obra, ansiedad imperial en torno a la emigración africana hacia el territorio de otros imperios y, por otro lado, la dificultad para determinar el status de los emigrantes individuales. ${ }^{4} \mathrm{El}$ trabajo de Eric Allina sobre el intento del gobierno colonial portugués de proteger y expandir sus reservas de mano de obra en Mozambique demuestra además que el reto de obtener trabajo por la fuerza fue algo común en territorios más grandes que la propia Guinea española. ${ }^{5}$ La interpretación de François Manchuelle acerca de la emigración laboral de soninkes anima a los historiadores a ver este fenómeno en términos de oportunidad, riqueza y tradición, más que en unos de desesperación, pobreza y ruptura. ${ }^{6}$ La emigración laboral nigeriana hacia Fernando Po se situó en algún punto entre la coerción abierta y el movimiento "libre"; ésta estuvo impulsada tanto por las expectativas de oportunidades económicas por el lado de los emigrantes individuales y por el lado del gobierno colonial español y sus agentes nigerianos.

3 Véase por ejemplo el mapa de Nigeria de Basil Davidson en el que aproximadamente toda la migración laboral es interna, dentro de la colonia. En DAVIDSON, B. (1994): Modern Africa: A Social and Political History. Longman, London, p. 28.

DOUGNON, I. (201 1): "Child Trafficking or Labor Migration?: A Historical Perspective from Mali's Dogon Country". Humanity, n 2, p. 85.

5 ALLINA, E. (1997): "Fallacious Mirrors:" Colonial Anxiety and Images of African Labor in Mozambique, ca. 1929". History in Africa, n. 24, p. 12.

6 MANCHUELLE, F. (1997): Willing Migrants: Soninke Labor Diasporas, 1848-1960. Ohio University Press, Athens, p. 4. 


\section{Emigración laboral nigeriana a Fernando Po}

La escasez de mano de obra había sido un problema de largo alcance en la Guinea española, iniciado por las guerras de ocupación que consolidaron el dominio español en los siglos XIX y XX y dieron lugar a una disminución de la población. ${ }^{7}$ Las políticas pronatalistas y los intentos por traer trabajadores de otras regiones del mundo tuvieron poco éxito a la hora de suplir a la colonia con un suministro constante de mano de obra. ${ }^{8}$ En las primeras décadas del siglo XX, la densamente poblada región de Nigeria oriental, accesible desde Fernando Po por medio de una corta travesía marítima, pasó a ser una atractiva fuente de mano de obra para el gobierno colonial español. Para los nigerianos orientales, especialmente para los igbos, la falta de oportunidades económicas en el ámbito local y el sistema de tenencia de la tierra que forzó a los jóvenes a buscarse el sustento lejos de sus hogares continuó estimulando la emigración a Fernando Po incluso después de que comenzaran a llegar noticias sobre las realidades que enfrentaban allí los trabajadores nigerianos. ${ }^{9}$

El problema de la mano de obra se agudizaría durante la Segunda Guerra Mundial, cuando la Guinea española se convirtió en una de las principales fuentes de productos tropicales para la España metropolitana. ${ }^{10} \mathrm{~A}$ lo largo de este periodo, se intensificó el reclutamiento clandestino en la Nigeria oriental. Esta mano de obra era nominalmente libre, pero en la práctica estaba fuertemente coaccionada. ${ }^{11}$ Aparecieron formas de reclutamiento cada vez más predadoras, hasta el punto que los nigerianos orientales las comparaban en algunas ocasiones con la esclavitud..$^{12}$ Entre el final de la Segunda Guerra Mundial y la independencia en 1968, el gobierno colonial de la Guinea española exigió numerosas obligaciones de trabajo gratuito de las comunidades indígenas fang y bubi. Cuando esta mano de obra se mostraba insuficiente, el gobierno español y sus agentes acostum-

7 CANTUS, L. (2007): "El comienzo de la masacre colonial del pueblo Bubi. La muerte del Botuko Sás, 1904". Centre d'estudis internacionals de biologia i antropologia, Barcelona, p. 25.

8 YGLESIAS DE LA RIVA, A. (1947): Política indígena en Guinea. Instituto de Estudios Africanos, Madrid, p. 266.

9 KORIEH, C. (2010): The Land Has Changed: History, Society and Gender in Colonial Eastern Nigeria. University of Calgary Press, Calgary, p. 253.

10 De forma general véase NERIN, G. (2008): Un guardia civil en la selva. Ariel, Barcelona.

11 HAILEY, M. (1968): An African Survey: A Study of Problems Arising in Africa South of the Sahara. Oxford University Press, London, p. 1376.

12 Véase, por ejemplo, Drum (West African Edition, Lagos), 'This Child Was Sold Into Slavery,' March 1958, p. 78. 
braban a centrarse en Nigeria, donde se dirigían a los jóvenes e impresionables prometiendo trabajo bien pagado y altos niveles de vida. ${ }^{13}$ Otros eran reclutados a través de métodos más contundentes, hasta el punto que las historias de patrullas de reclutamiento forzoso circulaban ampliamente por Nigeria oriental. Para muchos igbos estas variedades de "reclutamiento" eran similares al secuestro.

A pesar de todo, la emigración desde el este de Nigeria continuaba a buen ritmo, canalizaba por lo general a través del puerto de Calabar. Cuando llegaban a Fernando Po, los nigerianos pasaban a ser introducidos en un régimen de trabajo restrictivo que aseguraba una fuerza de trabajo estable a través de la limitación de movimiento de los trabajadores africanos, tanto autóctonos como extranjeros. ${ }^{14} \mathrm{~A}$ primeros de los años 60 los nigerianos componían cerca de un tercio de la mano de obra de la Guinea española. ${ }^{15}$ En Fernando Po, los nigerianos representaban la mayoría de la población; en cifras aproximadas hablamos de unos 85.000 sobre un total de 100.000 residentes. ${ }^{16}$ La gran mayoría de ellos eran igbos, cuya situación en la sociedad de la Guinea española era insegura a nivel social y legal, ello a pesar de que eran vitales desde un punto de vista económico. ${ }^{17} \mathrm{Tal}$ era la situación que España y Gran Bretaña negociaron varios compromisos sobre la regulación de la mano de obra nigeriana en Fernando Po, pero salvo en raras ocasiones ello no implicaba que las condiciones de bienestar estipuladas por los acuerdos fueran cumplidas.

Por su parte, el reclutamiento no estaba regulado, de manera que los agentes nigerianos responsables de dicha misión sobre el terreno eran pagados por sus jefes. A causa de ello fueron reclutadas muchas personas incapaces de realizar trabajos físicos, incluidos niños y ancianos incapaces de subsistir por sí mismos cuando llegaban a Fernando Po. Solamente en torno al veinte por ciento de los emigrantes eran mujeres, la mayoría de las cuales habían marchado con sus maridos. Las jornadas de trabajo podían superar las catorce horas, habitualmente no se cobraban los salarios y el castigo

13 SUNDIATA, I. (1990): Equatorial Guinea: Colonialism, State Terror, and the Search for Stability. Westview Press, Boulder, p. 41.

14 BELMONTE MEDINA, P. "Penología e indigenismo en la antigua Guinea española". Espacio, Tiempo y Forma, n 11, pp. 113-138.

15 OSUNTOKUN, A. (1978): Equatorial Guinea-Nigerian Relations: The Diplomacy of Labour. Oxford University Press, Ibadan, p. 50.

16 SUNDIATA, Equatorial Guinea, p. 47.

17 OYONO SA ABEGUE, V. (1985) : "L'évolution des structures productives et sociales de l'économie de la Guinée Équatoriale 1858-1968." Tesis Doctoral, Universidad de Lyon, p. 23. 
corporal estaba a la orden del día. Los administradores coloniales británicos comentaban que muchos de aquellos que volvían a Nigeria desde Fernando Po mostraban signos de haber sufrido abusos físicos. ${ }^{18}$ Los nigerianos tenían poco control sobre el destino que se les designaba para trabajar o el tipo de labores que habían de realizar. Aunque aquellos que habían inmigrado legalmente estaban nominalmente contratados al servicio de plantadores particulares en la práctica su destino era determinado por administradores españoles que "reclutaban" trabajadores "a aquella granja que en opinión de las autoridades sufre una mayor necesidad de mano de obra para mantener su producción media". ${ }^{19}$ Cuando los trabajadores tenían contratos los tribunales y administradores españoles los ignoraban de manera habitual, hasta el punto que para las autoridades españolas su condición de personas se limitaba a su capacidad para trabajar. Pero para los propios emigrantes y para aquellos que habían dejado atrás en Nigeria su experiencia como trabajadores tenía implicaciones importantes en cuestiones de nacionalidad e identidad política.

En estas circunstancias extremas, y muchas veces incapaces de pagar su billete de vuelta a casa, los nigerianos orientales acudían en busca de ayuda al consulado británico en Santa Isabel, quedando muy a menudo decepcionados con lo que el gobierno colonial les ofrecía. En los informes trimestrales elaborados por el vicecónsul para el Foreign Office queda muy clara esa indiferencia de las autoridades de la que se quejaban los nigerianos. Algunos cónsules despachaban sin más trámite a aquéllos que buscaban el apoyo de la misión diplomática y más tarde eran reprendidos por actuar así. Unos pocos permitieron a los nigerianos dormir en el suelo del consulado en los días siguientes a su audiencia con el vicecónsul, pero muchos regresaban de vuelta al interior de una ciudad donde no tenían permiso oficial para residir. ${ }^{20}$ Los funcionarios no sabían qué hacer con los trabajadores que recurrían a ellos en busca de ayuda, de manera que escribían a sus superiores en Londres, Brazzaville y Duala para pedir consejo, incluso en casos claros. Un vicecónsul escribió a un superior en Monrovia en 1944 para preguntar qué debía hacerse con una mujer sospechosa de ser una prostituta que había llegado al consulado después de ser violada por un policía. El cónsul británico respondió con nerviosismo

18 National Archives of the United Kingdom [en lo sucesivo NAUK] FO 371/108190, 'Confidential - From Brazzaville to Foreign Office,' 15 de septiembre de 1954.

19 NAUK FO 371/22669, Vice Consul, Santa Isabel to Vice Consul, Monrovia, 11 de julio de 1938.

20 NAUK FO 371/26908, "Labour Conditions in Spanish Guinea," 1946. 
que "no es costumbre de esta oficina decidir las cuestiones de Fernando Po". ${ }^{21}$ En este caso particular el vicecónsul decidió pagar el pasaje de dicha mujer para que pudiera regresar a Nigeria, pero en muchos otros la decisión era no actuar.

El vicecónsul británico se puso del lado del gobierno español en casos en que parecía que los nigerianos habían infringido de algún modo la ley, incluso si no estaba claro el contenido de la ley española que habían quebrantado. En 1938, los nigerianos se quejaban de estar siendo registrados en gran parte en busca de dinero y otros bienes que no estaban autorizados para acarrear consigo fuera de Fernando Po, al tiempo que los funcionarios portuarios españoles estaban confiscando bienes que supuestamente sí podían llevarse consigo los retornados. El caso es que el vicecónsul no se mostró empático. "He estado presente durante dichos registros en más de una ocasión", escribía, "pero hasta ahora no he visto ni una muestra del tratamiento brutal referido por los nativos en su carta colectiva al Secretario Jefe. La razón para llevar a cabo un registro exhaustivo tiene que ver con los múltiples intentos realizados, algo que continúa hoy, de pasar de contrabando plata de aquí". ${ }^{22}$ Sobreseimientos de este tipo enfurecieron a los trabajadores y a aquellos que habían dejado atrás en Nigeria.

Perder su escaso dinero a manos de los funcionarios españoles en su regreso a Nigeria no era el mayor de los problemas de los trabajadores nigerianos, de hecho el consulado decepcionó a los nigerianos en circunstancias mucho más directas que éstas. Cientos de nigerianos fueron encarcelados en prisiones españoles por crímenes reales e imaginados, y muchas muertes injustas nunca fueron investigadas. El asesinato de Ekpenyong Edem en 1945 fue uno de estos casos. Edem, descrito en el informe consultar como "original de Calabar, hijo de Okon y Adet Okon", trabajaba como porteador en una embarcación que operaba entre Fernando Po y la Guinea española continental. Cuando intentó desertar del barco en Santa Isabel el español que estaba al mando a bordo lo retuvo a la fuerza. Al hacerlo empujó a Edem al atracadero, acabando así con su vida. De hecho, como decía, hubo abundantes casos de muertes arbitrarias que implicaron a trabajadores nigerianos, muchos de los cuales no recibieron nada más que un párrafo en los informes trimestrales oficiales del consulado sobre relaciones laborales. Este caso fue de algún modo único porque Edem era un miembro de la marina mercante, de modo que la investigación se llevó a cabo de

21 NAUK FO 371/26904, Consul, Monrovia to Vice Consul, Santa Isabel, 8 de mayo de 1944

22 NAUK FO 371/22669, Vice Consul, Santa Isabel to Consul General, Monrovia, 4 de julio de 1938. 
forma más minuciosa que la mayoría. Sin embargo, no estaba más claro de lo que era habitual qué debía hacerse con su cuerpo, como tampoco estaba claro si debían tomarse medidas en los tribunales españoles contra su patrón. En la breve descripción del informe del vicecónsul sobre los orígenes de Edem y en su declaración de que era una Persona Británica Protegida [a British Protected Person] no prescribía ningún procedimiento a seguir en concreto. Identificar al individuo en cuestión era por lo general todo lo que podía hacer el consulado. En este caso, el vicecónsul se sintió obligado a escribir a su superior en Duala "de modo que puedas informar a las autoridades nigerianas de los hechos y notificarme, si es necesario, qué medidas se están llevando a cabo o qué medidas deben ser adoptadas por mí". He aquí un reconocimiento tácito de que era poco lo que se podía hacer para llevar a la justicia a aquellos que acababan con las vidas de los nigerianos o abusaban de ellos. En el caso de Edem la implicación del consulado terminó cuando el informe del incidente fue archivado. No se prosiguieron acciones legales contra el patrón de la embarcación y los restos de Edem no fueron repatriados. ${ }^{23}$

El gobierno colonial nigeriano envió un mensaje contradictorio sobre reclutamiento ilegal de mano de obra en el sureste. A finales de los años 30 los británicos habían creado una fuerza policial especial para combatir ese sistema predador de obtención de trabajadores por parte de los plantadores españoles y sus agentes nigerianos, pero la policía nigeriana sólo persiguió a los traficantes de manera esporádica. ${ }^{24}$ Una serie de ordenanzas de trabajo aprobadas a principios de los 50 estipularon una multa de quinientas libras o cinco años de prisión para los reclutadores que no registraran de forma adecuada a los emigrantes, sin embargo este castigo sólo fue aplicado en muy raras ocasiones. ${ }^{25} \mathrm{En}$ un caso que se dio a conocer ampliamente en 1954, la policía de Calabar arrestó a dos empleados nigerianos de una firma española por "obtener pasaportes para los emigrantes bajo la falsa declaración de que marchaban a Fernando Po como comerciantes," 26 pero este arresto fue una excepción en medio de la incapacidad general del gobierno para hacer valer las regulaciones en materia de emigración. De vez en cuando, incluso no estaba claro cuáles eran las regulaciones; éstas cambiaban constantemente, y los funcionarios no se

23 NAUK FO 371/49598, Vice Consul, Santa Isabel to Consul General, Douala, 30 de enero de 1945

24 OSUNTOKUN, Equatorial Guinea-Nigerian Relations, p. 30.

25 West African Pilot, 25 de agosto de 1954, p. 1.

26 West African Pilot, 21 julio de 1954, p. 1. 
ponían de acuerdo sobre qué organismo del gobierno nigeriano tenía la autoridad para permitir a los emigrantes marchar o para prevenirlos frente a ello. Las instituciones gubernamentales, desde la policía municipal de Calabar hasta el Protectorado de Nigeria Meridional emitieron documentos de forma independiente los unos de los otros, y hasta mediados de los 50 no hubo consenso sobre qué implicaba un proceso de registro adecuado. ${ }^{27}$ Desde los años 30 a los 50, los documentos consulares ponen de manifiesto una profunda inquietud entre los miembros del servicio diplomático británico con respecto a sus obligaciones para con los trabajadores nigerianos, así como también sobre los procedimientos apropiados a seguir en casos de abusos. La ambigüedad en torno a la nacionalidad de los implicados y la ausencia de un protocolo diplomático claro para lidiar con sus casos atrapó a los nigerianos en un vacío diplomático. La situación se exacerbó por el alto índice de rotaciones en el personal administrativo -Fernando Po no era un destino atractivo para los miembros del servicio diplomático, de modo que sólo en raras ocasiones los vicecónsules y los funcionarios encargados de cuestiones laborales permanecían en sus puestos más de un año. Los cierres esporádicos del consulado hicieron que fuera difícil para su reducido personal desarrollar cualquier tipo de política estable o consistente hacia los nigerianos necesitados de asistencia. A pesar del hecho que el personal del consulado recibía al menos diez casos urgentes a la semana en el momento álgido a mediados de los años 50, la institución no desplegó una política coordinada. Las respuestas a casos de abusos continuaron siendo en gran medida improvisadas.

En Fernando Po la responsabilidad de salvaguardar los intereses de las Personas Británicas Protegidas contradecían habitualmente la orden de mantener buenas relaciones con España. Cuando se trataba de decidir si defender a los nigerianos, y en este caso posiblemente poner en peligro las relaciones diplomáticas británicas con España, o por el contrario rechazar que había una crisis y arriesgarse a alienar a los nigerianos, los vicecónsules británicos tendían a elegir la segunda opción. Los funcionarios consulares británicos expresaron dudas en privado sobre su capacidad para dar protección a los trabajadores nigerianos frente al estado colonial español, sin embargo presentaban una imagen muy diferente a la prensa nigeriana y al Foreign Office en Londres. Las relaciones diplomáticas con la España de Franco fueron frágiles a lo largo de todo el periodo objeto de estudio aquí. Como resultado de ello, los funcionarios consulares se mantuvieron

27 NAUK FO 371/60392, "Status of British West Africans in the Spanish Territories," septiembre de 1945 . 
de forma constante al margen de las denuncias públicas contra España, al tiempo que rechazaron que la situación requiriera medidas que fueran más allá de la asistencia consular normal. Un editorialista en el West African Pilot especulaba con la idea de que el gobierno británico era reticente a reconocer públicamente lo extendido de los abusos españoles porque Gran Bretaña quería ocultar su incapacidad para interferir en las actuaciones y decisiones españolas, al menos a ojos de sus súbditos nigerianos, que supuestamente veían al imperio británico como omnipotente. ${ }^{28}$

Los predicadores protestantes que daban guía espiritual a los emigrantes igbos a veces se veían envueltos en esta representación de equilibrio político. En una investigación de dos policías que fueron acusados de azotar a un nigeriano acusado robo en Santa Isabel, el vicecónsul Eric Twigge-Molecey utilizó el testimonio de un pastor metodista para asegurar al Foreign Office que no había razones para preocuparse en la Guinea española. "El reverendo Shepherd me informa", escribía, "que ha hecho investigaciones muy exhaustivas entre los miembros de su congregación y en todos los casos el resultado ha sido el mismo... que ellos consideraban que el tratamiento que estaban recibiendo ahora no dejaba nada que desear". ${ }^{29}$ Ciertamente, no fue esta por lo general la reacción más común; otros pastores estaban tan frustrados con las condiciones de vida que enfrentaban sus feligreses y con la incapacidad del consulado británico para intervenir que apelaron a la Sociedad para la Protección de los Aborígenes [Aborigins' Protection Society]. ${ }^{30}$

Aunque los nigerianos sin papeles se encontraban en la situación más precaria, los trabajadores que seguían todos los protocolos de emigración adecuados se encontraban con que apenas podían recurrir a la asistencia consular a la que teóricamente tenían derecho. El caso de Sunday Achonu, un carpintero de Ukwu que solicitaba al consulado un pasaje con destino a Nigeria después de haber sido robado, ilustra bien esta realidad. Achonu no sólo tenía su documentación en orden, sino que estaba alfabetizado y era un trabajador cualificado. De algún modo se había procurado un informe policial de las autoridades españolas demostrando que había sido robado y que no había la ley española, todo lo cual planteaba un caso sólido y convincente para proveer asistencia consular en forma de dinero o de un pasaje de vuelta a casa. Sin citar ni una sola razón el vicecónsul de-

28 West African Pilot, 22 de marzo de 1946, p. 2.

29 NAUK FO 371/22669, Vice Consul, Santa Isabel to Consul General, Monrovia, 4 de agosto de 1938.

30 NAUK FO 371/49598, M. Jenkins to Vice Consul, Santa Isabel, 8 de junio de 1945. 
cidió no hacerlo. ${ }^{31}$ No hay pruebas de que hubiera un complot consciente por parte de los funcionarios y diplomáticos consulares o los negociadores de acuerdos laborales para abandonar o subordinar a los trabajadores igbos en particular. Sin embargo, abandono e indiferencia por parte de las autoridades fueron los mensajes que llegaron a Nigeria oriental, y su percepción -sin entrar a considerar si tal cosa era cierta-conformó la percepción popular del lugar que los igbos ocupaban dentro de Nigeria y el imperio británico. Desde su perspectiva, las garantías legales prometidas por el imperio parecían cada vez más falsas y vacías a lo largo del periodo final del dominio colonial.

\section{Agravios igbos y separatismo en Biafra}

Los escándalos continuaron sucediéndose en Fernando Po a lo largo de los años 50, creando por lo general descontento civil en Nigeria oriental. En 1958, las noticias de que un comerciante español en Calabar había estado subastando pertenencias de trabajadores nigerianos fallecidos catalizó amplias manifestaciones públicas en ese mismo puerto. Lo mismo ocurrió en Aba y Enugu tras una mediática serie de asesinatos de emigrantes de origen nigeriano en Fernando Po. ${ }^{32}$ No está claro que fue lo que se dijó en esas manifestaciones o qué era exactamente lo que pedían quienes se congregaron en ellas. Sin embargo, las críticas aparecidas en la prensa de Nigeria Oriental son un poco más claras. Éstas recogieron una ira considerable frente al maltrato de los trabajadores, percibiendo la indiferencia del consulado ante esta situación. Esto llevó a algunas personas a cuestionarse si los británicos eran los más adecuados para defender el bienestar de los igbos en el extranjero. Un periodista preguntaba, "¿qué tiene que esperar [de parte del funcionario británico de trabajo en Fernando Po] la gente sino indiferencia y falta de interés real por lo sufrimientos del pobre trabajador? Como cónsul británico tiene una mansión y un espléndido salario. No tiene nada que temer, pero todo y todos tienen que temerlo y adorarlo. Y viviendoen reclusión, tal y como él lo hace, al trabajador africano le es denegado no sólo un acceso fácil al cónsul británico, sino que también enfrenta el desalentador espectro del 'castiga' [castigo] si se atreve a quejarse contra su amo español." ${ }^{33}$ En este caso el gobierno nigeriano se sintió obligado a responder públicamente a la crítica, asegurando en una carta al editor que

31 NAUK FO 371/26911, "Labour Conditions in Spanish Guinea," 1950.

32 Eastern States Express, 11 May 1958, p. 1.

33 West African Pilot, 20 December 1948, p. 2. 
"la queja sobre la indiferencia y falta de interés real de su parte contradice todo los informes previos, tanto oficiales como no oficiales". ${ }^{34}$

El hecho de que la mayoría de los emigrantes fueran igbos no era un tema de discusión para los funcionarios consulares, pero sí que lo era de forma muy evidente para esta comunidad. Mucha gente interpretó la naturaleza ad hoc de la asistencia consular y la actitud de no compromiso de los diplomáticos como prueba de la deserción británica respecto a los igbos que continuó viva en el periodo posterior a la independencia. A principios de los 50, la devolución del control directo de los británicos al gobierno nigeriano, incluyendo a los administradores nigerianos, conllevó que aquéllos a cargo de asegurar el bienestar de los igbos también cambiaron. Aunque los funcionarios del servicio diplomático británico todavía era formalmente responsables de la asistencia consular, muchos nigerianos fueron destinados al consulado. Y lo que es más importante, africanos miembros del gobierno nigeriano se encontraban en posición de hacer algo con la situación reinante en Fernando Po. A ojos de muchos igbos, la visita en 1953 de Samuel Akintola, ministro nigeriano de trabajo, fue una prueba importante del compromiso del gobierno nigeriano con la protección de esta comunidad. Aunque Akintola tuvo éxito a la hora de negociar un incremento del $25 \%$ en los salarios de aquellos que habían llegado ilegalmente, la mayoría de la sociedad de Nigeria oriental vio en su visita un fracaso. Akintola volvió a Lagos afirmando que no había pruebas del maltrato español contra los trabajadores igbos -una conclusión que parecía contradecir el constate flujo de emigrantes retornados de Fernando Po físicamente rotos y en la indigencia. Las visitas posteriores fueron exitosas a la hora de lograr las promesas españolas de hacer cumplir las provisiones de protección social, que en teoría estaban vigentes desde los años 40 , a pesar de que los abusos continuaron en las plantaciones. No deja de ser significativo que Akintola fuera yoruba, procedente de una región al oeste de Nigeria que no había sido afectada por el reclutamiento de mano de obra para Fernando Po. Los periodistas y políticos de Nigeria oriental mencionaban este hecho para afirmar que el gobierno nigeriano no estaba interesado en el bienestar de los igbos, tal y como ya había ocurrido con las autoridades británicas. ${ }^{35}$

La independencia formal de Nigeria en 1960 no cambió sustancialmente la situación en la Guinea española. Las acusaciones de los igbos de impotencia y traición por parte del gobierno de su país continuaron, pero no fueron dirigidas a la República Federal de Nigeria. Después de 1960 algo se

34 West African Pilot, 23 December 1948, p. 1.

35 West African Pilot, 8 July 1958, p. 2. 
puso de manifiesto de manera dolorosa para los trabajadores emigrantes: si la categoría de Persona Británica Protegida servía de poco a modo de protección aún podía ofrecer menos el gobierno nigeriano. El Foreign Office británico se preocupó de que el gobierno nigeriano independiente no sería capaz de destinar suficientes recursos para la protección de sus ciudadanos en Fernando Po, y el consulado permaneció bajo la administración del organismo metropolitano durante el año 1961. El último caso que fue investigado por un vicecónsul británico implicaba a un capataz español en la finca de Pradesa que golpeaba a sus trabajadores y "lanzaba habitualmente a su perro tras ellos cuando intentaban escapar de sus castigos". ${ }^{36}$ Como la mayoría de los demás, el caso quedó sin respuesta ni solución.

La prensa de Nigeria oriental se refirió habitualmente a las dificultades de los trabajadores en Fernando Po como "crisis", y para muchos observadores esa crisis duró más de treinta años. De forma similar a otras comunidades nigerianas fuera del país, los trabajadores emigrantes en Fernando Po se encontraron en lo que C. Bawa Yamba ha denominado en un contexto similar como un "estado de liminalidad prolongado". ${ }^{37}$ Los acuerdos en materia de trabajo iban y venían y los gobiernos tenían grados de interés variables en el bienestar de los nigerianos en Fernando Po, pero las dinámicas migratorias permanecieron en buena medida similares a lo largo de todo el periodo comprendido entre los años 30 y 60 . Incluso cuando las políticas de descolonización estaban reconfigurando la región en aspectos importantes, los igbos continuaron siendo explotados en Fernando Po. Sus gobiernos continuaron estando bloqueados respecto a lo que hacer con ellos; hacia el año 1965 un emigrante nigeriano en Fernando Po estaría atrapado en una situación muy similar a la que podía haber vivido su padre en 1935. Los igbos de Nigeria oriental que habían sobrevivido a la experiencia de ser enviados ilegalmente a Fernando Po, y aquellos que todavía tenían familiares allí, mencionaban la aparente impotencia de su gobierno para protegerlos como una razón entre otras invocadas por los territorios orientales del país para perseguir un camino político independiente respecto a la República Federal de Nigeria.

A lo largo de los años 60, en Nigeria oriental se estaba fraguando una confrontación política. En julio de 1966, seis años después de que Nigeria hubiera conquistado su independencia de Gran Bretaña y seis meses después de que un golpe militar hubiera derribado la Primera República

36 NAUK FO 371/154686, "Confidential Report," 4 de mayo de 1961.

37 BAWA YAMBA, C. (1995): Permanent Pilgrims: The Role of Pilgrimage in the Lives of West African Muslims in Sudan. Edinburgh University Press, Edinburgh, p. 2. 
nigeriana, un grupo de generales del norte del país organizó otro golpe y situó al teniente general Yakubu Gowon como jefe de estado. A finales de ese mismo año, en los momentos posteriores a los hechos estallaron una serie de pogromos contra los igbos y otras comunidades de la región oriental del país que vivían en el norte, la mayoría de los cuales se habían asentado allí a lo largo del siglo XX como mercaderes y empleados del gobierno. En tres meses fueron asesinados entre 80 y 100.000 igbos a lo largo de los territorios septentrionales de Nigeria. El gobierno del país se veía incapaz de parar los pogromos, dando a mucha gente la impresión de que éstos estaban planeados y sancionados en realidad por el nuevo régimen militar de Nigeria. ${ }^{38}$ Entre tres y cinco millones de igbos y otras comunidades procedentes de la parte oriental del país "regresaron" al lugar de origen de sus familias como resultado de la violencia. Después de un periodo de negociaciones no concluyentes, en mayo de 1967 los territorios del este se separaron como la República de Biafra, esencialmente sobre la base de que Nigeria había fracasado para proteger a los ciudadanos de dicha región -y especialmente a los igbos- residentes en otras partes del país. El líder de Biafra era el teniente coronel Chukwuemeka Odumegwu Ojukwu, un oficial que había sido elevado a la condición de soldado nigeriano modelo. En cualquier caso, Nigeria no estaba dispuesta a perder los territorios reivindicados por Biafra, en buena medida porque la mayor parte de sus reservas de petróleo estaban localizadas allí. El gobierno impulso una "acción policial" para recuperar el este del país, algo que no tardó en dar lugar a una escalada hacia una auténtica guerra.

Aunque Biafra consiguió congregar un grado importante de solidaridad internacional, Nigeria tenía clara ventaja en términos militares. Después de la captura de Port Harcourt en mayo de 1968 Biafra quedó aislada del mundo exterior, dando como resultado además una gran hambruna. Los combates duraron hasta la derrota de Biafra en enero de 1970, dando lugar a un número muy alto de bajas civiles -el número preciso es objeto de debate. La vida cotidiana en Biafra fue extremadamente difícil; las muertes por hambre, los bombardeos, las amenazas internas a la libertad como las levas obligatorias fueron cada vez más comunes conforme la guerra avanzaba, hechos que en algunos casos fueron recogidos por la prensa internacional, que mostró un marcado interés por el conflicto. Después de la rendición de Biafra sus territorios fueron reintegrados en Nigeria, y esto

38 Para una historia detallada de este preludio de la guerra véase ANTHONY, D. (2002): Poison and Medicine: Ethnicity, Power, and Violence in a Nigerian City, 1966 to 1986. Heinemann, London y OSAGHAE, E. (1998): Crippled Giant: Nigeria Since Independence. Indiana University Press, Bloomington, p. 63. 
fue posible porque el gobierno militar nigeriano persiguió una política en la que reclamaba que no había habido "ni vencedores ni vencidos" -lo cual se plasmó en un proceso de reconciliación nacional en el que los ciudadanos ordinarios de origen igbo que habían combatido por la independencia de Biafra no serían castigados, al tiempo que les sería permitido reclamar las propiedades que muchos de ellos habían dejado atrás en otras partes de Nigeria. Se trató de un proceso polémico, y el coste humano y material de la guerra se continuaría sintiendo mucho después de que ésta finalizara.

\section{De emigrantes a soldados: la conscripción en la República de Biafra}

El tránsito entre Nigeria y Fernando Po se ralentizó durante la guerra, pero incluso en los momentos más desesperados de la lucha nunca se frenó del todo. Muchos igbos que ya estaban en la Guinea española en el momento en que se produjo la secesión de Biafra permanecieron allí durante toda la guerra, habitualmente en circunstancias miserables. Sea como fuere, en octubre de 1968la Guinea española se independizó de España bajo el nombre de Guinea Ecuatorial, con Francisco Macías Nguema como jefe de estado, pero esta transición (por el momento) no cambió sustancialmente la economía agraria de Fernando Po, incluyendo su dependencia de la mano de obra emigrante nigeriana. En cualquier caso, la economía agrícola de la antigua colonia española se estancó durante la guerra, y sólo tras el final del conflicto se reanudaría el flujo de mano de obra forzada. Guinea Ecuatorial mantuvo unas relaciones complicadas con Biafra, y Fernando Po (rebautizada Bioko tras la independencia) jugó un pequeño aunque importante rol desde el punto de vista táctico durante el conflicto. A mediados de 1968, cuando la isla todavía estaba bajo control español, las negociaciones entre el Comité Internacional de la Cruz Roja y el gobierno nigeriano desembocaron en un acuerdo por medio del cual la isla sería utilizada como base de operaciones para vuelos de asistencia y socorro con destino a Biafra, siempre sometida a inspección por parte de Nigeria. ${ }^{39}$ El gobierno Macías puso fin a este acuerdo por deseo de Nigeria, una decisión que también estuvo motivada por el miedo a que la numerosa población igbo de la isla pudiera intentar unirla a una Biafra independiente. Sin embargo, la política fue ejecutada de forma inconsistente y Guinea Ecuatorial continuó permitiendo ocasionalmente vuelos de auxilio desde Bioko. ${ }^{40}$

39 NAUK FCO 38/303, International Committee of the Red Cross, Press release, 25 de agosto de 1968.

40 STREMLAU, J. (1977): The International Politics of the Nigerian Civil War. Princeton University Press, Princeton, p. 285. 
Pero las políticas de humanitarismo internacional y diplomacia no fueron las únicas vías por las cuales los acontecimientos en Guinea Ecuatorial influyeron en la guerra civil nigeriana. También hubo una importante continuidad entre la memoria y práctica de la emigración igbo a Fernando Po y el estallido de la guerra; más que ser "conscriptos" para el trabajo agrícola en la isla, ahora los jóvenes se vieron reclutados para el servicio militar en el ejército biafrano. Aunque existían diferencias innegables entre el reclutamiento para el trabajo agrícola y la conscripción militar, las similitudes entre estas formas de trabajo forzoso fueron evidentes para muchos jóvenes igbos que habían experimentado ambas realidades. Las dos formas de coacción fueron violentas $y$, también de forma muy similar, permanecieron sin regular. Este tipo de conscripción -irregular, coaccionada y llevada a cabo por agentes que no respondían ante nadie que no fueran ellos mismos- era marcadamente similar al modo en que había operado la emigración laboral a Fernando Po durante las tres décadas previas a la guerra. ${ }^{41}$ La base documental con que contamos a la hora de realizar la historia de la conscripción en Biafra es mucho más pequeña que para lo que se refiere a la cuestión laboral en Fernando Po, pero la historia oral y la documentación del gobierno biafrano revelan que muchos combatientes de las tropas de su ejército tenían alguna experiencia como trabajadores en Fernando Po. No es posible contabilizar el número de soldados biafranos que habían trabajado allí, pero las escasas fuentes archivísticas de Biafra sugieren que en algunas regiones de la antigua república secesionista la proporción era alta. Los documentos del reclutamiento en el ejército biafrano del primer año de la guerra centrados en el área en torno a Calabar recogen que muchos de los hombres que fueron reclutados en el ejército habían viajado a Fernando Po, y unos pocos habían sido multados por el gobierno colonial por haberlo hecho. ${ }^{42}$

La conscripción fue un aspecto extremadamente importante de la historia social de la guerra en Biafra. Los civiles biafranos soportaron una buena parte de la violencia del conflicto, pero en algunos casos la más incisiva tuvo lugar en el contexto del reclutamiento militar. En los primeros meses de la guerra circulaba por Biafra un panfleto propagandístico representando a un niño de diez años vestido con un uniforme holgado. La leyenda decía: "no hay nadie demasiado pequeño o demasiado grande para la gran tarea de defender la patria. El joven 'oficial' de arriba a jurado traer de vuelta diez cabezas de soldados nigerianos en estricta obediencia a su

41 Nigerian National Archives, Calabar [en lo sucesivo NNAC] 609 CAD 396/1/vol. x 3/3/356, "Recruitment Into Biafra Army," 7 de julio de 1967.

42 NNAC 609 CAD 396/1, "Register of men recruited into army," s.f. [1967]. 
obligación para con la nación". ${ }^{43}$ Esto no significaba que una afirmación así hubiera de tomarse al pie de la letra al principio de la guerra, pero en sus compases finales el ejército biafrano contaba entre sus filas tanto con niños como con ancianos. La conscripción de adolescentes, hombres de edad avanzada y de los incapacitados física y mentalmente no era "legal", pero estuvo tan extendida en Biafra que de forma frecuente se dieron notificaciones judiciales en los tribunales de la república. ${ }^{44}$ La conscripción fue mucho más despiadada en la práctica que sobre el papel. Las empresas, las parroquias y las instituciones gubernamentales podían pedir al gobierno de Biafra eximir a sus empleados del servicio militar, pero eso no podía ponerlos a salvo de ser conscriptos por milicias y por unidades aisladas del ejército. ${ }^{45}$ Las campañas de conscripción fueron un rasgo permanente de la vida en la nueva república. Éstas dieron a los soldados una autoridad sin límites para detener hombres de cualquier edad y origen y podía servir también como pretexto para diferentes formas de extorsión. La coerción violenta de la mano de obra que tal situación implicó recordaba a algunas personas al trabajo forzoso del periodo colonial, incluyendo comparaciones explícitas con lo vivido en Fernando Po. ${ }^{46}$

Los asuntos de vida y muerte habitualmente se volvieron en contra de la conscripción. Un administrador escribió a una provincia que no había cumplido con los objetivos de reclutamiento que "las negligencias e indiferencia a la hora de lidiar con el problema son un suicidio. Bien podéis entender porqué se considera que cualquier población que falla a la hora de contribuir plenamente a los requerimientos de nuevas tropas trabaja contra los intereses de Biafra. La advertencia no será repetida". ${ }^{47} \mathrm{~A}$ las diferentes poblaciones se les hizo saber que eran responsables de la concentración y transporte de sus hombres hacia un punto de encuentro establecido donde serían contados e inmediatamente reclutados por el ejército. Las consecuencias en caso de no alcanzar el número requerido de hombres eran serias. Una circular del ejército advertía que "el fracaso a la hora de cumplir

43 Biafra Sun, 12 de julio de 1967, p. 5.

44 Por ejemplo en el siguiente caso judicial: Nigerian National Archives, Enugu [en lo sucesivo NNAE] MINJUST 116/1/8, En el Tribunal Especial de Biafra, Holden en Nbawsi, No. ST/24c/69, The State v. Benedict Emene, 18 de noviembre de 1969.

45 National War Museum, Umuahia [en lo sucesivo NWM] colección no catalogada, H.E. Meniru, B.G.C. Ltd. To Chairman, Civil Defence, Orlu, 30 de julio de 1969.

46 Colecciones no catalogadas del NWM, "Provincial Zone F Defense," 27 de noviembre de 1969.

47 Colección no catalogada del NWM, "Recruitment into the Biafran Army," 15 de noviembre de 1969. 
con esta directiva obligará al mando a poner en marcha una conscripción abierta en todas las localidades que no respondan al llamamiento tal y como se espera. Por lo tanto estáis advertidos de que hacer uso de esta oportunidad poniendo a disposición a vuestros varones es la mejor manera de evitar las penalidades de la conscripción". ${ }^{48}$ De hecho, las campañas de conscripción fueron por lo general punitivas, y mucha gente recuerda que en los compases finales de la guerra "el único momento en que verías un hombre en uniforme es si éste estaba intentando reclutar hombres o recaudar dinero". ${ }^{49}$ En el último año de la guerra uno de los modos en que el gobierno biafrano estaba más presente en la vida de las personas era a través de la recogida de impuestos para la compra de material militar. Los de mayor envergadura eran los "impuestos a discreción" [jet levies], que reclamaban a las localidades recaudar cientos de libras en efectivo y en especia, teóricamente para adquirir aviones de combate, pero en realidad la mayor parte de las veces para mantener la solvencia financiera del gobierno de Biafra. Habitualmente, los pueblos eran incapaces de reunir el dinero que se les pedía, y cuando no lo lograban eran seleccionados para ser sometidas a campañas de reclutamiento particularmente brutales. ${ }^{50}$

Tal y como había ocurrido con el reclutamiento de mano de obra, la conscripción militar fue desorganizada y arbitraria. Conforme la guerra avanzó fue en disminución la consistencia de los métodos mediante los cuales eran reclutados los hombres y dejó de estar claro incluso para el gobierno biafrano quién estaba autorizado para llevar a cabo levas o quién podía ser movilizado. En la práctica cualquier hombre de casi cualquier edad podía ser forzado a hacer el servicio militar. La conscripción significaba una pérdida de libertad inmediata e irreversible, llegando a afectar ocasionalmente a las mujeres, aunque no fuera lo más común. De hecho, cuando un grupo de muchachas fue sumado a los reclutas enviados a un campo militar cerca de Orlu un oficial las rechazó. ${ }^{51}$ El trabajo de los hombres físicamente aptos fue también requisado para tareas auxiliares como cavar trincheras. A medidos de 1968 no había uniformes que entregar ni apenas adiestramiento que impartir a los nuevos reclutas, y eran afortunados si recibían un arma antes de ser enviados al frente. Hacia el final de la guerra

48 Colección no catalogada del NWM, "Recruitment into the Commando," 25 de junio de 1969.

49 Entrevista con Barrister Mike Onwuzunike, Holy Ghost Cathedral, Enugu, 14 de septiembre de 2014

50 Colección no catalogada del NWM, Civil Defence Committee, Umuobom to Provincial Secretary, Orlu, 26 de septiembre de 1969.

51 Colección no catalogada del NWM. "Recruitment into BA," [1969]. 
la conscripción se había convertido, tal y como reflejaban las quejas de un burócrata biafrano, una batalla campal. ${ }^{52} \mathrm{El}$ caos y la arbitrariedad del proceso fue una reminiscencia del reclutamiento para Fernando Po, aunque a una escala más extrema de lo que había ocurrido en este último caso.

\section{Conclusión}

Es un cliché de la historiografía nigeriana que los igbos que componían la mayor parte de la población de Biafra eran "extraños" dentro de la propia Nigeria. Muchas historias del siglo XX en Nigeria señalan esta cuestión haciendo referencia a la guerra civil y a los pogromos que condujeron a esta. ${ }^{53}$ De hecho, esta percepción de marginalidad es el producto de una historia que va más allá en el tiempo. La experiencia de los emigrantes laborales en Fernando Po en una parte importante de la historia nigeriana del siglo pasado, incluyendo su guerra civil, así como también es parte de la historia del colonialismo español. Dicha experiencia tuvo implicaciones políticas al otro lado del mar, en Nigeria, que fueron mucho más allá del valor económico del trabajo que hicieron. Reducir a los emigrantes a su trabajo los hace sólo partes alienables de un sistema económico, cuando lo cierto es que sus experiencias y sus acciones fueron importantes para los debates sobre el status personal y el significado de la protección en el imperio británico y en la Nigeria independiente -debates que llegarían a un punto crítico en la forma de una guerra civil. Las dinámicas que hicieron posible la emigración laboral a Fernando Po no fueron tan diferentes de aquéllas que llevaron a los hombres al ejército biafrano, y para muchos jóvenes igbos las miserias que acarrearon estas experiencias fueron de algún modo igual de duras. Identificar las formas en que el trabajo forzoso puede ser similar al servicio militar -o puede ser percibido como tal- nos ofrece nuevas vías para comprender tanto el trabajo como la vida del soldado.

52 NNAE MINJUST 21/1/2, M.O.I. Idigo to Solicitor-General, Enugu, 17 de marzo de 1969.

53 Este argumento es planteado de formas diversas en, por ejemplo, OJELEYE, O. (2010): The Politics of Post-War Demobilisation and Reintegration in Nigeria. Ashgate, Aldershot y OYEWESO, S., ed. (2000): Perspectives on the Nigerian Civil War. Campus Press, Lagos. 


\section{Bibliografía}

ALLINA, E. (1997): "Fallacious Mirrors:" Colonial Anxiety and Images of African Labor in Mozambique, ca. 1929". History in Africa, n. 24.

ANTHONY, D. (2002): Poison and Medicine: Ethnicity, Power, and Violence in a Nigerian City, 1966 to 1986. Heinemann, London.

BAWA YAMBA, C. (1995): Permanent Pilgrims: The Role of Pilgrimage in the Lives of West African Muslims in Sudan. Edinburgh University Press, Edinburgh.

BELMONTE MEDINA, P. "Penología e indigenismo en la antigua Guinea española". Espacio, Tiempo y Forma, n 11.

CANTUS, L. (2007): "El comienzo de la masacre colonial del pueblo Bubi. La muerte del Botuko Sás, 1904". Centre d'estudis internacionals de biologia i antropologia, Barcelona.

DAVIDSON, B. (1994): Modern Africa: A Social and Political History. Longman, London, p. 28.

DOUGNON, I. (201 1): "Child Trafficking or Labor Migration?: A Historical Perspective from Mali's Dogon Country". Humanity, n 2.

ESIEMHOKAI, E. (1986): The Colonial Legal Heritage in Nigeria. Fagbamigbe Publishers, Akure.

HAILEY, M. (1968): An African Survey: A Study of Problems Arising in Africa South of the Sahara. Oxford University Press, London.

KORIEH, C. (2010): The Land Has Changed: History, Society and Gender in Colonial Eastern Nigeria. University of Calgary Press, Calgary.

MANCHUELLE, F. (1997): Willing Migrants: Soninke Labor Diasporas, 1848-1960. Ohio University Press, Athens.

OJELEYE, O. (2010): The Politics of Post-War Demobilisation and Reintegration in Nigeria. Ashgate, Aldershot.

OSAGHAE, E. (1998): Crippled Giant: Nigeria Since Independence. Indiana University Press, Bloomington.

OSUNTOKUN, A. (1978): Equatorial Guinea-Nigerian Relations: The Diplomacy of Labour. Oxford University Press, Ibadan.

OYEWESO, S., ed. (2000): Perspectives on the Nigerian Civil War. Campus Press, Lagos.

OYONO SA ABEGUE, V. (1985) : "L'évolution des structures productives et sociales de l'économie de la Guinée Équatoriale 1858-1968." Doctoral dissertation, University of Lyon. 
STREMLAU, J. (1977): The International Politics of the Nigerian Civil War. Princeton University Press, Princeton.

SUNDIATA, I. (1990): Equatorial Guinea: Colonialism, State Terror, and the Search for Stability. Westview Press, Boulder.

YGLESIAS DE LA RIVA, A. (1947): Política indígena en Guinea. Instituto de Estudios Africanos, Madrid. 